\title{
Ethnic origin of the victim as an aggravating factor in sentencing sexual offenders
}

\author{
Karen Harrison \& Aisha K. Gill
}

To cite this article: Karen Harrison \& Aisha K. Gill (2017) Ethnic origin of the victim as an aggravating factor in sentencing sexual offenders, Journal of Sexual Aggression, 23:3, 300-311, DOI: $10.1080 / 13552600.2016 .1267271$

To link to this article: https://doi.org/10.1080/13552600.2016.1267271

册 Published online: 16 Jan 2017.

Submit your article to this journal $\pi$

Џll Article views: 154

Q View related articles $₫$

View Crossmark data 


\title{
Ethnic origin of the victim as an aggravating factor in sentencing sexual offenders
}

\author{
Karen Harrison ${ }^{\mathrm{a}}$ and Aisha K. Gill ${ }^{\mathrm{b}}$

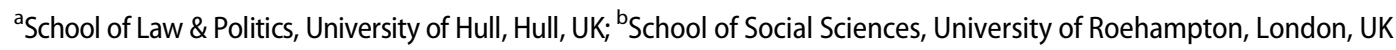

\begin{abstract}
This article examines $\mathrm{R} v$ Jamal Muhammed Raheem UI Nasir, a Court of Appeal case where leave to appeal against a seven-year custodial sentence for sexual offences against children was refused. The appellant argued that his sentence length was excessive because the judge viewed the female victims' ethnic and religious origin as an aggravating factor. In light of a number of charities' condemning the judgment, this article evaluates whether the Court of Appeal made the correct decision, particularly in the wider context of sentencing principles. It also considers whether causing shame to a victim and her family can be regarded as an aggravating factor when sentencing sexual offences, and discusses the circumstances where the victim's ethnic origin should be taken into account.
\end{abstract}

ARTICLE HISTORY

Received 21 June 2016

Revised 18 November 2016

Accepted 25 November 2016

\section{KEYWORDS}

Shame; sentencing principles; aggravating factors; South Asian victims

\section{Introduction}

The 2015 judgment of the Court of Appeal in $R \mathrm{v}$ Jamal Muhammed Raheem UI Nasir (Court of Appeal (Criminal Division), 10 September 2015) has been met with criticism from both children's charities and women's survivor groups. It has been described as an "injustice" (The Mirror, 17 September 2015, http://www.mirror.co.uk/news/uk-news/paedophile-who-abused-two-young-6463908) and as going against the cornerstone of British justice: that is, that everyone is equal before the law (The Yorkshire Post, 17 September 2015, http://www.yorkshirepost.co.uk/news/critics-round-on-judgewho-upheld-harsher-sentence-for-abuser-who-targeted-asian-girls-1-7467600). In this article, we question such views and consider whether the Court of Appeal's judgment, which upheld the sentencing judge's original decision, was correct. The judgment confirmed that, in sexual abuse cases where the victim is of South Asian ethnic origin, it is considered correct to treat the victim differently from others and to take into account the shame that she and her family may have experienced as a consequence of the offence. In so ruling, the Court of Appeal's judgment maintained that it is appropriate to include shame as an aggravating factor to increase a custodial sentence.

In this analysis, we look at the principles that must be followed when criminal sentencing decisions are made, particularly in relation to cases involving a sexual offence. We set out the brief facts of the case, summarise the judgment and reflect on how some charities and other organisations have reacted to it. Drawing on the academic literature and original empirical research, we define shame and consider the effect it can have on women and children who reside in South Asian communities in England and Wales. We proceed to demonstrate that the Court of Appeal was correct in its judgment, while, however, also commenting on the category of victim to whom this judgment should apply, and arguing that this factor should not be limited to South Asian victims exclusively. 


\section{Background}

The case against Jamal Muhammed Raheem UI Nasir was that he had sexually abused two girls, aged 9 and 13, respectively. In terms of criminal convictions, this equated to two counts of sexual assault on a child under 13 (Sexual Offences Act 2003, s.7) and four counts of sexual activity with a child (Sexual Offences Act 2003, s.9). When sentencing criminal cases, judges must follow certain principles, many of which are contained within the Criminal Justice Act 2003. Current sentencing policy works on the basis of a just deserts model, whereby a person receives a custodial sentence only if the offence in question is serious enough to warrant such a sentence. The gravity of the offence or offences in question must, therefore, be commensurate with or balanced against the severity of the proposed penalty. As part of the decision-making process, sentencing judges also determine the seriousness of the circumstances of a particular crime. Seriousness is defined in both legislation and a Sentencing Council guideline. Section 143(1) of the Criminal Justice Act 2003 states: "In considering the seriousness of any offence, the court must consider the offender's culpability in committing the offence and any harm which the offence caused, was intended to cause or might foreseeably have caused." This focus on culpability and harm is echoed in the Sentencing Council's guideline which states: "The seriousness of an offence is determined by two main parameters: the culpability of the offender and the harm caused or risked being caused by the offence" [emphasis in original source] (Sentencing Guidelines Council, 2004, p. 3). A note clarifies the order of priority in terms of harm and culpability, stating that, while the level of harm caused is important, "the culpability of the offender in the particular circumstances of an individual case should be the initial factor in determining the seriousness of an offence" (Sentencing Guidelines Council, 2004, p. 5). The guideline identifies four levels of criminal culpability: intention, recklessness, knowledge and negligence. Intention, framed as the worst level, creates the greatest degree of culpability. The guideline also provides examples of factors that are indicative of higher culpability, such as the offence being religiously or racially aggravated or there being an abuse of power or a position of trust. Likewise, factors that might suggest a lower level of culpability include mental illness and disability. Harm can be defined in terms of the effect that the crime has or may have on individual victims or the community.

In addition to helping judges determine how serious a given crime is, the Sentencing Council has also issued a number of definitive guidelines on specific topics and crimes. The aim of these guidelines is to ensure transparency and consistency in sentencing and thus all guidelines issued by the Sentencing Council are binding in all courts in England and Wales (Coroners and Justice Act 2009, s. 125(1)). The Sexual Offences Definitive Guideline on sentencing sexual offences has been in force since 1 April 2014 and, therefore, would have been applicable in $R v$ Jamal Muhammed Raheem UI Nasir. Covering more than 50 sexual offences, the Sexual Offences Definitive Guideline is a large and multifaceted document. Despite this complexity, it is clear that the impact of the offence on the victim is central to the principles contained within it. When deciding on a sentence, the court must consider not only the physical harm an offence has caused to the victim, but also the psychological trauma and long-term effects resulting from the offence. In addition to providing a specific guideline for each sexual offence, and in line with the principle that seriousness is made up of both culpability and harm, the Definitive Guideline specifies three category ranges in terms of harm and two levels of culpability. For example, an offence under Section 7 of the Sexual Offences Act 2003 (sexual assault of a child under 13) where "violence or threats of violence" are present is classed within Category 1 in terms of harm (Sentencing Council, 2013, p. 38). Culpability is divided into " $A$ " and " $B$ " categories, with the factors listed in " $A$ " indicating a higher level of culpability. Again, for a Section 7 offence, factors categorised under " $A$ " may include a significant degree of planning, an abuse of trust or situations where the offender has deliberately isolated the victim (Sentencing Council, 2013, p. 38).

Once the judge has determined the most appropriate categories for harm and culpability, the Guideline provides the following table to determine the relevant starting point from which to calculate the provisional sentence (Table 1). 
Table 1. Starting point and category ranges for Sexual Offences Act (Section 7, Sentencing Council, 2013, p. 39).

\begin{tabular}{lll}
\hline & \multicolumn{1}{c}{ A } & \\
\hline Category 1 & Starting point & B \\
& 6 years' custody & Starting point \\
& Category range & 4 years' custody \\
Category 2 & $4-9$ years' custody & Category range \\
& Starting point & $3-7$ years' custody \\
& 4 years' custody & Starting point \\
Category 3 & Category range & 2 years' custody \\
& $3-7$ years' custody & Category range \\
& Starting point & $1-4$ years' custody \\
& 1 years' custody & Starting point \\
& Category range & 26 weeks' custody \\
& 26 weeks' -2 years' custody & Category range \\
\hline
\end{tabular}

Thus, under Section 7 of the Sexual Offences Act 2003, the starting point for an offence where there has been severe psychological harm (Category 1 ) and a significant degree of planning (Category A culpability) is a custodial term of six years, with a category range of four to nine years (Sentencing Council, 2013, pp. 38-39). The tariff can then be increased or lowered depending on the existence of mitigating or aggravating factors and reduced through the entering of a timely guilty plea. Aggravating factors could include blackmail, the presence of previous convictions and attempts to dispose of or conceal evidence; meanwhile, mitigation could include evidence of remorse or "previous good character" (Sentencing Council, 2013, p. 39). While the currently published list of aggravating factors does not include any reference to the victim's ethnic origin, the Definitive Guideline does nevertheless point out that this list is "non-exhaustive" and that other relevant factors can be taken into account when deciding on the most appropriate sentence (Sentencing Council, 2013, p. 39).

\section{Judgment}

Decided upon in September 2015, the case of $R$ v Jamal Muhammed Raheem UI Nasir involved a renewed application to the Court of Appeal for leave to appeal against the sentence, following a single judge's refusal of an initial appeal. The appellant wanted to appeal against the seven-year sentence handed down by Her Honour Justice Cahill QC in Leeds Crown Court on 18 December 2014. As previously outlined, UI Nasir had been found guilty of two counts of sexual assault of a child under 13 (Sexual Offences Act 2003, s.7) and four counts of sexual activity with a child (Sexual Offences Act 2003, s.9). The victims, two girls, one aged 9 and one 13 at the time of the offences, were referred to as $\mathrm{J}$ and $\mathrm{G}$ in the judgment. Both girls were of South Asian origin. The appellant received two concurrent sentences of four years' imprisonment for the offences committed against $J$ and four concurrent sentences of three years' imprisonment for the offences against $G$; these sentences ran consecutively and made up the seven-year term.

Three main points formed the basis of the appellant's argument that his sentence of seven years was excessive. The first two points related to the initial starting point used by the sentencing judge and whether or not she had taken the principle of totality into proper account. The totality principle applies when the judge is sentencing an offender for more than one offence. In such circumstances, the judge must consider whether the total sentence given is just and proportionate to the offending behaviour. In the case discussed, both these appeal points were quickly dismissed. The third point, and the subject of this article, referred to the argument that Her Honour Justice Cahill QC had regarded the offending as aggravated because of the victims' ethnic and religious origin and thus, on that basis, had added time on to the sentence. The point at issue for the Court of Appeal was, therefore, whether it was proper to take such factors into account when deciding on the most appropriate sentence.

Consequently, the South Asian ethnic background of both J and G and the offender, coupled with the issue of shame in this community, is of special significance in this particular discussion. Referring to the remarks of the sentencing judge, Justice Walker highlighted that $J$ was having difficulties at 
school because her friends knew about the attacks and this knowledge had led to shame being placed upon her. Likewise, G was also experiencing problems at school. In addition, G's father described how the whole family was struggling to deal with the situation because the offences had brought shame not just to his daughter but to the entire family. The family felt they were being isolated by the community because of this shame. In addition, G's father was concerned not only about the marital prospects of $G$, but also those of all his daughters. The sentencing judge further noted how, being South Asian in origin and coming from the same community as the victims, UI Nasir was fully aware of the effect that the offences would have on the victims and their families and that this knowledge was an additional aggravating factor. The Court of Appeal agreed that these were all important points. Justice Walker argued that the particular harm caused to the victims in this case was aggravated by the additional impact the victims and their families had to suffer in their own communities, namely shame and consequent isolation. Leave to appeal, on this point, was, therefore, refused.

\section{Reaction}

The judgment received a moderate amount of press coverage and mixed comment from children's charities, victim organisations and others. The National Society for the Prevention of Cruelty to Children (NSPCC), for example, was somewhat negative in its response:

British justice should operate on a level playing field and children need to be protected irrespective of cultural differences ... Regardless of race, religion, or gender, every child deserves the right to be safe and protected from sexual abuse, and the courts must reflect this. It is vital that those who commit these hideous crimes are punished to the full limit of the law. (The Telegraph, 17 September 2015, http://www.telegraph.co.uk/news/ uknews/law-and-order/11871975/Child-molester-given-longer-sentence-as-victims-are-Asian.html)

This view was also supported by Jasvinder Sanghera, founder of Karma Nirvana, a charity working with survivors of honour-based abuse. Commenting on the case, she said: "We feel this judgment provides an injustice to other victims of similar sexual abuse that are not from a South Asian Community. The 'shame' factor highlighted in this case is a common feature for all victims of sexual abuse" (The Mirror, 17 September 2015, http://www.mirror.co.uk/news/uk-news/paedophile-who-abused-twoyoung-6463908). Philip Davies, MP for Shipley, West Yorkshire additionally argued:

To suggest that to sexually abuse Asian girls is more serious than sexually abusing white girls is completely unacceptable ... One has to wonder from where they manage to dig up these politically correct judges ... The principle that everyone is equal before the law - once the cornerstone of British justice - appears to have been thrown out of the window. (The Yorkshire Post, 17 September 2015, http://www.yorkshirepost.co.uk/news/ critics-round-on-judge-who-upheld-harsher-sentence-for-abuser-who-targeted-asian-girls-1-7467600)

Such views were not shared unanimously, however. Diana Nammi of the Iranian and Kurdish Women's Rights Organisation said: "I think there's truth in the argument that Asian girls can suffer greater consequences within their own communities. It's a reality borne out by our experiences" (The Yorkshire Post, 17 September 2015, http://www.yorkshirepost.co.uk/news/critics-round-onjudge-who-upheld-harsher-sentence-for-abuser-who-targeted-asian-girls-1-7467600). The fundamental question here is, therefore, whether the imposition of shame should be regarded as an aggravating factor when sentencing cases of sexual abuse and whether it is proper to use the existence of this dishonour to increase an offender's sentence.

\section{Honour and shame}

Before this question is considered, it may first be useful to understand what the concepts of both honour and shame mean in South Asian communities. Honour (izzat in Urdu) is arguably one of the most significant facets of South Asian culture and it is generally seen to dwell in the bodies of women (Coomaraswamy, 2005). In honour-based societies, husbands and fathers are defined as 
the heads of the family and thus the defenders of its honour. As such, all men are expected to protect their family, particularly its female members, against any behaviour that might be seen by the wider community as dishonourable or humiliating (Gill, 2017). A family's honour or prestige is achieved and, importantly, maintained through the conduct, actions and social performances of its women; consequently, familial interests take precedence over individual ones. Moreover, since izzat relies on the behaviour of women, the duty to safeguard the family's honour has been argued to afford men the right to exercise control over women's bodies and behaviour (Cowburn, Gill, \& Harrison, 2014). Thus, men in South Asian cultures are often socialised and expected to act as "controllers of women's sexuality" (Abraham, 1999, p. 597), which gives rise to a variety of social norms concerning what is and is not acceptable in relation to women's sexual practices. Coomaraswamy (2005), for example, argues that "women who fall in love, engage in extramarital relationships, seek a divorce or choose their own husbands are seen to transgress the boundaries of 'appropriate' (that is socially sanctioned) sexual behaviour" (p. xi). Welchman and Hossain (2005a) go further and argue that such transgressions can even include "staying out late and smoking" (p. 5).

The corollary to honour is shame (sharam in Urdu). When honour is lost, it is replaced by shame. The "dishonoured" woman is then "punished", often through forms of social ostracism and harassment (Siddiqui, 2005). In extreme situations, and in an attempt to re-establish family honour, shame is remedied through so-called honour-based violence, which can also include subsequent honour-killings (Gill, 2017). Some women also inflict acts of extreme violence upon themselves in order to save others from the impact of shame. Siddiqui (2005), for example, tells of a case where a woman hanged herself in shame after discovering that her husband was going to divorce her and marry a younger woman. The husband had spread rumours of adultery against his wife in order to facilitate the divorce. Knowing that these allegations, coupled with the stigma of the divorce, would reflect badly on her "family honour" and ruin the marriage prospects of her two daughters, the woman decided to kill herself (Siddiqui, 2005, p. 264). Shame is, therefore, not just limited to the shamed/dishonoured woman. In some cases, as highlighted in $R v$ Jamal Muhammed Raheem UI Nasir, the shame and dishonour extends out to encompass siblings, parents and children, who may all accordingly experience isolation and abuse from others in the extended family and community at large.

Shame even occurs when the loss of honour is not directly attributable to the behaviour of the woman. For example, in circumstances where sexual abuse has taken place, although it seems reasonable to assume that the shame should be placed upon the perpetrator of the sexual crime rather than on the victim, this is often not the case. In South Asian Hindi- and Urdu-speaking communities, the expressions most commonly used when talking about rape are meri izzat looti gayi (Hindi) or meri izzat lut gayi (Urdu); both versions translate roughly as "I could not prevent them from stealing my honour" (Cowburn et al., 2014; Gill, 2010). Message-board discussions examining the use of these terms in Bollywood films question why such language is tolerated, given that it implicitly lays the blame for tarnished honour on abused women. Izzat lut gayi - "not being able to hold on to her honour" - linguistically suggests that honour resides in female reproductive organs and, consequently, is vulnerable to being lost when a violent sexual assault takes place. Importantly, this wording additionally implies that it is the victim who is at fault for losing her izzat, thereby placing responsibility for the shame with the victim and not the perpetrator (Gill, 2010).

\section{Empirical research}

A recent empirical study, conducted by us, reaffirms both the importance of izzat and the potential consequences of sharam in British South Asian communities. The project was underpinned by our belief that, despite evidence of lower sexual abuse reporting rates in South Asian communities (Gilligan \& Akhtar, 2005), sexual abuse occurred on a similar level as that found in all other communities in England and Wales. The aims of the project were, therefore, two-fold: (1) to discover the barriers preventing British South Asian women and children from reporting sexual abuse and, (2) to evaluate 
what more could be done to encourage increased reporting. The study's findings on why British South Asian women and children are reluctant to report sexual abuse are relevant here. The project took a mixed methodology approach and used focus groups and semi-structured interviews to gather as many general viewpoints as possible. We began the research by holding four focus groups with women living in British South Asian communities. Two were held in the Midlands, one in the North of England and one in the South. Approximately 85 women participated in the research. In all cases, non-governmental organisations (NGOs) brokered the meetings. At the midway stage of the research, we also held two focus groups with imams (religious administrators of mosques) and other community representatives. One of these meetings took place in the North of England and the other in the greater Midlands area.

In addition to the general opinions provided by the focus groups, we also interviewed 13 British South Asian victim-survivors of sexual abuse, some of whom had experienced historical abuse as children. These women were recruited either through the NGOs or personal contacts. We also spoke to 13 professionals from NGOs who worked with such victims and 13 other professionals who came from either criminal justice agencies or government departments (both local and national). These professionals included nine police officers from four police areas, all of which had relatively high South Asian populations, in addition to one Chief Prosecutor, one high ranking civil servant (who had responsibility for protecting vulnerable adults and children in one of the police areas under consideration), a local policy officer and a policy lead in national government.

Data collection for the project took place over the period of May 2013 to June 2015. For the purpose of the research, the term "South Asian" was used to refer to (i) people born in the Asian sub-continent (ie India, Pakistan and Bangladesh) living in Britain and (ii) people of South Asian heritage born in Britain. To acknowledge that these groupings belong to the British community while still being connected to their original and historic roots, the phrase "British South Asian" is used throughout the article.

We found that women and children from British South Asian communities fail to report incidents of sexual abuse for a myriad of reasons (Gill \& Harrison, 2016). Although many of the reasons proffered to explain the failure to report sexual abuse transcend all populations and are, therefore, not exclusive to this particular community, one of the headline findings from our study is that silence, in terms of not reporting, stems from a fear of losing honour and subsequently bringing shame onto oneself and one's family. The following quotes taken from interviews with victim-survivors highlight this point:

If I tell my mom or I tell my dad, what are they going to say to me? How dare you say something like that ... then it's "hush, hush" and don't talk about it. You're going to degrade yourself; you're going to disgrace us in the community. It's a huge thing disgracing your family name within the Asian community, then that leads to, "She's been abused, she's not going to be marriageable material anymore, and nobody in the community is going to touch her. Everybody's going to cut us off."

If I tell, then they are gonna tell somebody else and everybody's gonna know and then it's gonna bring shame on the family ... It's gonna be a stain on my reputation. Nobody's gonna want to marry me, nobody's gonna ... I've got younger sisters. Nobody's gonna want to marry them.

That feeling the issue of shame; the husband might be raping the wife; it might have been throughout their marriage, but she's told to keep patient. He might change. If you try to leave, the family might say: "Well we're not having you, it's your marriage, you deal with it, and you know you've gotta work at it" and also "What will the community say? It'll look bad." And also it might be that if it's a relative involved in the abuse: "Well his family who're related to us are gonna get really upset."

Another young woman in the study, who was being treated as a domestic slave by her mother-in-law and sexually abused by her husband, explained why she could not return to her parents' house:

You can't depend on your family [once you are married], so many people say that the community will feel ashamed if you leave [an abusive marriage]. They don't kill you with a knife or anything, but they kill you emotionally: the talking, the gossip behind your back. 
Family honour is so important that, in some circumstances, the needs of the family are placed before those of an abused child. One victim-survivor, who was sexually abused by an uncle and cousin when she was seven, recounted what happened when she finally found the courage to disclose the abuse to her mother:

You're brought up on these notions of respect, izzat ... [but] when a family continues to communicate with the abuser's family, who have gone on to abuse the victim when she's told them about what's happened... To reinforce that victim by blaming the girl for what happened when she was seven and by the family being complicit and acquiescent in just simply not standing up to them and saying: "What was done was wrong and you owe it to my daughter to apologise to her." The fact that very basic justice that's supposed to take place within familial structures, the notion of extended family, the notion of culture, the notion of community has left me dumbfounded, has left me numb and frankly has left me with no expectations, no idea ... no sense of wanting anything from them anymore.

Another explained how "It's all conditional love in Asian families and that's what honour is all about ... There is no unconditional love in Asian families. Honour is more important to them than their own child's happiness."

Victim-survivors also told of a need to be wary with regard to what would happen to them physically if their "honour" was lost. One victim-survivor, who was abused as a child, waited until her parents had died before reporting her abuse to the police; in order to avoid embarrassing them and having the community disown both her and her extended family. She explained:

They would have hurt me somehow. I've heard of it before. They would have chucked me out of where I live; they would have caused a lot of trouble. I've heard of other cases where girls ... They just wouldn't be very nice.

All of the NGO representatives were also aware of the problems presented by the loss of honour. One stated:

... Many young girls, for instance, will hold responsibility for the honour within their family if it's perceived that their honour is lost. Even if the family believe and are supportive to them, the possible consequences for them can be huge, which can range from being rejected from the family or from the community, their marriage prospects, potentially honour-based violence, forced marriage. There can be so many consequences for them coming forward.

The interviewee extracts above clearly demonstrate the monumental impact of sexual abuse in terms of a victim losing her honour.

\section{Should shame be an aggravating factor in sentencing sexual abuse cases?}

Returning to the main point of appeal in $R v$ Jamal Muhammed Raheem UI Nasir, the key question is whether the imposition of shame on others should be regarded as an aggravating factor when sentencing cases of sexual abuse. In debating this issue, it is worth reiterating some of the central points made by the Sentencing Council: specifically, that the sentencing judge must show regard to the psychological trauma and long-term effects resulting from the sexual abuse, along with the fact that the list of aggravating factors is non-exhaustive. The guidelines hold that, provided the factor under consideration is relevant to the particular circumstances, the judge has every right to include it as an aggravating factor and thus use it to increase sentence length. As evidenced in the academic literature and our recent empirical study, the effects of losing honour can be devastating for a British South Asian female. For this reason, loss of honour constitutes a particularly relevant aggravating factor in terms of the sexual abuse of a woman/girl in the context of Britain's South Asian communities. Not only can the loss of honour affect the victim's current everyday life, in terms of stigma and isolation, it can also be a permanent life-changing factor affecting not just her own marital prospects, but potentially also those of her siblings and cousins. In extreme cases, loss of honour can also lead to violence against the person and even death. Referring to the terminology used by the Sentencing Council, shame, therefore, has the clear potential to be classified as causing both severe psychological trauma and long-term effects, thereby indicating that it should 
indeed be taken into account when a sentencing decision is made. However, the question of whether it is correct to take shame into account as an additional aggravating factor in a sentencing decision as it was by the sentencing judge in $R v$ Jamal Muhammed Raheem UI Nasir - nonetheless remains. When looking at shame and its consequential effects, it is clear that these can amount to severe psychological trauma for the victim in question. As explained above, shaming can result in the female being side-lined by her family and community, living in fear for her own safety and having to bear the heavy responsibility of having brought stigma upon her family, even when she is in no way culpable.

For a Section 7 offence (sexual assault of a child under 13), the Sexual Offences Definitive Guideline lists "severe psychological or physical harm" (Sentencing Council, 2013, p. 38) as a harm factor, with the existence of it placing the offence into Category 1 in terms of the harm caused. In this instance, it would, therefore, appear appropriate that shame, as a severe form of psychological trauma should be properly classified under harm and that its existence should have an influence for sentencing purposes - only to the extent that the sentence can recognise the level of harm caused as more serious. Following this line of argument, the imposition of shame in $R v$ Jamal Muhammed Raheem UI Nasir should consequently have been used to increase only the starting point from which the sentencing judge would have initially set the sentence. In this scenario, and for this particular offence, it can be argued that shame is not an aggravating factor per se, but rather that it influences the category of harm.

However, the other offence under consideration in this case was sexual activity with a child (Sexual Offences Act 2003, section 9), an offence of which the appellant was found guilty on four counts. Dissimilar to the approach outlined above, the Definitive Guideline for a section 9 offence classifies "severe psychological or physical harm" (Sentencing Council, 2013, p. 48) as an additional aggravating factor. The reasoning behind the two offences dealing with this same element in two distinct ways is unclear; further discussion on this issue is perhaps worthy of another article. Nevertheless, on the basis that the sentencing judge must follow the published guideline, two conclusions regarding these section 9 offences can, arguably, be drawn: (1) that the sentencing judge in $R v$ Jamal Muhammed Raheem UI Nasir was wholly accurate in addressing the existence and effects of shame as an additional aggravating factor and (2) that doing so correctly allowed her to increase the sentence after the initial starting point had been identified.

An additional viewpoint is that psychological trauma and future marriage prospects are two distinct forms of harm and any detriment to these should, therefore, be classified as long-term effects rather than as psychological trauma. Despite the Sentencing Council stating that both forms of harm are equally important when undertaking a sentencing decision, it is only severe psychological trauma that is specifically mentioned in the offence-specific guidelines. On the basis that the list of additional aggravating factors is non-exhaustive and that long-term effects are not mentioned elsewhere, it is argued here that the effects of shame in terms of long-term impacts should, therefore, be taken account of at the aggravating factor stage, rather than being seen only as features that can increase harm. While a victim-survivor may get to a stage where she is able to live with the trauma of her abuse, she may never be able to influence or alter her chances of marriage once her honour has been irretrievably lost. In this additional sense, the sentencing judge was, therefore, wholly correct to treat the detrimental effects on the victim's future marital prospects as an additional aggravating factor.

Sentencing judges are also allowed to take into account harm caused to not just individual victims but also to the community. While the phrase "community" is not defined in the Definitive Guideline, "community" could arguably be used to refer to both nuclear and extended families. Defining community in this wider way would, therefore, allow the sentencing judge to take into account not only the harm caused to the actual victim of the sexual abuse, but also any harm caused by association, such as the shame felt by parents, siblings and members of the extended family in terms of isolation, stigma and marriage prospects. 
Furthermore, the appellant in this case, coming from the same ethnic background as the victims in question, knew the impact that losing honour would have on these girls; indeed, this point was made by the sentencing judge herself. He was clearly aware that, in addition to the "normal" traumas associated with child sexual abuse, he would be causing shame to his victims and their families, along with all the consequential effects that such shame would bring. While it may be an overstatement to suggest that the appellant intended to cause this additional damage, it can nonetheless be argued that he appreciated, or was at least reckless in his disregarding of it, thereby making him arguably more culpable for his actions. It is, of course, fair to say that, unless he knew the victims' families intimately, the appellant would not have been aware of the potential strength of their reactions on discovering that the girls had been sexually abused, nor of any consequences that this knowledge might have had for $J$ and $G$. However, while there is no suggestion here that $J$ and $G$ 's families behaved violently towards either of them, there is ample evidence in the academic literature and our recent empirical study to suggest that South Asian families, along with their wider community, can and do retaliate against victims of sexual abuse through personal violence and even threats of death. The fact that the appellant recklessly and knowingly subjected the girls to such potential additional risk must, consequently, be seen as another additional aggravating factor. It is, therefore, our view that the Court of Appeal was correct in stating that, in the case of $R v$ Jamal Muhammed Raheem UI Nasir, the ethnic origin of the victims aggravated the offence and thus made it more serious.

\section{Who else might this judgment apply to?}

While, as expressed above, we agree with the Court of Appeal's decision in the case of $R v$ Jamal Muhammed Raheem UI Nasir, that agreement is in no way meant to belittle or undervalue the trauma that all children, men and women suffer when they have been subjected to crimes of a sexual nature, irrespective of the community from which they come. We do, however, disagree with the viewpoint that all victims should be treated in exactly the same way when weighing the nature of that trauma. Rather, we contend that it is sometimes essential to consider individuals according to their specific needs and circumstances in order to ensure they have actually received equal justice. Here we wish to emphasise the point that it is important for the courts to give due consideration to the fact that trauma may take distinct social as well as physical and emotional forms, and that some forms of social trauma may have more long-lasting and far-reaching consequences for some victims than for others. This argument is based on the fact that the long-term effects of sexual abuse can be amplified in some circumstances, one of these being when the victim comes from a community where a very specific view of honour and shame underpins the victim's culture and upbringing.

It is nonetheless important to stress that the cultural importance given to honour and shame is not limited exclusively to South Asian communities. So-called honour-crimes have been reported in Egypt, Palestine, Jordan, Iraqi Kurdistan, Latin America and several Nordic countries (Gill, 2017; Welchman \& Hossain, 2005b). This claim is further supported by anecdotal evidence from the research interviews highlighted above, where interviewees from the NGOs stated that honour and shame are issues that also control women in Polish, Chinese and Romany communities. It is, therefore, clear that shame and its stigmatising effect on women and children should be regarded as an aggravating factor when sentencing offenders for sexual crimes.

As mentioned earlier, shame is a major motivator in women's silence and family and social image are highly valued in South Asian cultures that expect women to uphold traditional values. As a result, individual women who risk the good name of their families by exposing personal information about their experiences of sexual abuse leave themselves open to being branded as having acted in a shameful manner (Feiring, Taska, \& Chen, 2002; Gill \& Harrison, 2016). That said, it is, however, important to note here that individual victims are subject to many social, psychological and demographic characteristics that potentially affect whether or not they feel shame and the 
extent of it when they do. The issue of shame, in turn, gives rise to a practical consideration regarding the way in which consideration of it is then put into practice by the courts. In short, if shame is judged to be either a valid factor in assessing the degree of harm or an aggravating factor, it must apply to all victims, regardless of the cultural heritage, ethnicity or religion of the victim and despite the fact that, in some cases, the cultural background of the victim may make addressing the issue of shame somewhat easier for the court. Taking that approach, however, begs the question of how the court should deal with cases where cultural, ethnic or religious factors are not as easily identified as relevant. Here, there is a possible danger that some victims' shame could be less recognised, or less valued, than that of others because they do not come from certain identified cultures where shame and family and community honour are perceived to have great currency and impact.

While the decision in the case of $R v$ Jamal Muhammed Raheem UI Nasir clearly placed responsibility on the individual perpetrator for the contextual impact of the offences, this case, nonetheless, provides an opportunity for further reflection on how the courts respond to victims of sexual violence more generally and how that response might be improved. First, judges need to be cognizant of how shame impacts on women's experiences of speaking of sexual violence in the court room. Second, legal professionals should be educated to understand the harm associated with sexual violence and the ways in which shame acts as a barrier to recovery, because any failure of understanding in this regard could put victims at unnecessary risk. Given that the keystone of the British legal system is that everyone is equal, it, therefore, holds that the justice system must judge everyone according to the same principles.

There is also an urgent need to disrupt patriarchal structures in our society beyond the legal system. Women in all communities continue to struggle for freedom from sexual violence and sexual discrimination, because society has not transformed the traditional dichotomies that elevate the masculine and degrade the feminine. Challenging sexual violence involves disrupting patriarchy, as the ideology behind it and the social structures that form as a result of it serve to make such violence permissible. Belief systems that allow crimes of sexual violence to occur in certain cultures and contexts are ingrained to the extent that the possibility of effecting change goes beyond the capability of simply the law. For instance, more work is needed to understand the challenges that sexually abused women face in terms of reuniting with their respective communities and families, as this reintegration may be traumatic and shameful for the returning victim who may experience not only ostracism from her family and community, but also internal trauma and selfrepudiation stemming from feelings of shame. Here, the external impact of the offence committed against her is felt in terms of exclusion from family members, partners and communities who do not want to be associated with victims and who may distance themselves from those who have spoken out about sexual abuse within their midst. The internal impact refers to the struggle such women may face in terms of their own sense of shame and violation resulting from the sexual abuse. In summary, these abuse victims are not only experiencing estrangement from their most intimate support systems, but also dealing with their own feelings of shame, guilt, and mental and emotional anguish.

Other attitudes that further isolate the victim/survivor from the community include those informed by the assumption that the victim in some way complied with the attack and also the belief that the victim was used and or ruined (MacKinnon, 2006). The subsequent dishonour and violation associated with this slur on the victim's character breed shame and guilt, which can, in turn, result in both personal and community rejection. Such repudiation isolates individuals from communities and destroys the economic, societal and familial functioning of the community where women have traditionally played pivotal roles. Sexual violence also revolves around gender relations and sociocultural dynamics. Understanding and engaging with these embedded values are, therefore, necessary in order to address sexual abuse within any community (Wilson, Drozdek, \& Turkovic, 2006). 


\section{Conclusion}

The issues of honour and shame are real, powerful and potentially damaging to women and children living in cultures where certain cultural attitudes to these norms and values are prevalent. It is, therefore, welcome that in the case of $R v$ Jamal Muhammed Raheem UI Nasir the Court of Appeal acknowledged the aggravating effect that shame and loss of honour have on some British South Asian victims of sexual abuse. However, in order that this application of the law can be consistent, it is important that the courts acknowledge such aggravation not just for South Asian victims, but also for those from non-Asian communities. Irrespective of the communities and cultures from which they come, all women, children, and men deserve to live their lives free from violence and abuse. For the vulnerable in our societies, violence is a daily threat and common occurrence; consequently, more must be done to prevent its occurrence. To that end, the courts must hold all offenders fully responsible for their actions, including punishing offenders to the fullest extent of the law, and thereby demonstrating that there will be consequences for both their offending and the ramifications of it on their victims.

With reference to Philip Davies' comments mentioned earlier (The Yorkshire Post, 17 September 2015), we are not arguing that sexually abusing South Asian girls is more serious than sexually abusing white girls per se. We do, however, argue that loss of honour must be considered a relevant factor when sentencing, simply because this loss can lead to victims and their families having to directly endure the impact of this shaming on their reputations and marriage prospects for many years to come. This opprobrium can, in turn, also cause them to suffer social isolation and, potentially, violence. Regardless of the ethnic background of the victim, the very real possibility of such harm should be seen as an aggravating factor that makes the offence more serious, especially in cases where the offender is well aware that such dire consequences will follow from his/her actions.

In summary, shame is a relevant factor when sentencing child sex offenders, but it is not one that pertains exclusively to South Asian victims or to children only. In addition to tackling sexual crimes, we argue that there is also a need to eradicate so-called honour-based violence. Thus, the Court of Appeal's judgment in the case of $R v$ Jamal Muhammed Raheem UI Nasir may represent a small step towards creating a wider understanding of some of the social and cultural issues that impact on many women and children living in minority ethnic communities in England and Wales and the impact of sexual violence against them.

\section{Acknowledgement}

Many thanks to the anonymous reviewers for their valuable comments on an earlier draft of this paper. We would also like to thank Professor Gerry Johnstone (University of Hull) and Professor Tony Ward (Northumbria University). Any errors are of course our own.

\section{Disclosure statement}

No potential conflict of interest was reported by the authors.

\section{Funding}

This work was supported by British Academy [grant number SG122150].

\section{References}

Abraham, M. (1999). Sexual abuse in South Asian immigrant marriages. Violence Against Women, 5, 591-618.

Coomaraswamy, R. (2005). Violence against women and crimes of honour. In L. Welchman \& S. Hossain (Eds.), Honour crimes, paradigms and violence against women (pp. xi-xiii). London: Zed Books.

Cowburn, M., Gill, A., Harrison, K. (2014). Speaking about sexual abuse in South Asian communities: Offenders, victims and the challenges of shame. Journal of Sexual Aggression, 4-15. http://dx.doi.org/10.1080/13552600.2014.929188 
Feiring, C., Taska, L., \& Chen, K. (2002). Trying to understand why horrible things happen: Attribution, shame, and symptom development following sexual abuse. Child Maltreatment, 7(1), 25-39.

Gill, A. (2010). Violence against women in South Asian communities in the UK: A culture of silence. In C. McGlynn \& V. Munro (Eds.), Rethinking rape law: International and comparative perspectives (pp. 308-321). London: RoutledgeCavendish.

Gill, A. (2017). Women murdered in the name of "honour". In F. Brookman, E. R. Maguir \& M. Maguire (Eds.), The handbook on homicide. Chichester: Wiley Blackwell.

Gill, A., \& Harrison, K. (2016). Police responses to intimate partner sexual violence in South Asian communities. Policing: Journal of Policy and Practice. doi:10.1093/police/paw027

Gilligan, P., \& Akhtar, S. (2005). Cultural barriers to the disclosure of child sexual abuse in Asian communities: Listening to what women say. British Journal of Social Work, 36(8), 1361-1377.

MacKinnon, C. (2006). Genocide's sexuality. In C. MacKinnon (Ed.), Are women human? (pp. 209-236). Cambridge, MA: Harvard University Press.

Sentencing Council. (2013). Sexual offences definitive guide. London: Author.

Sentencing Guidelines Council. (2004). Overarching principles: Seriousness. London: Sentencing Guidelines Secretariat.

Siddiqui, H. (2005). There is no honour in domestic violence, only shame! Women's struggles against honour crimes in the UK. In L. Welchman \& S. Hossain (Eds.), Honour. Crimes, paradigms and violence against women (pp. 263-281). London: Zed Books.

Welchman, L., \& Hossain, S. (2005a). Honour rights and wrongs. In L. Welchman \& S. Hossain (Eds.), Honour. Crimes, paradigms and violence against women. London: Zed Books.

Welchman, L., \& Hossain, S. (Eds.). (2005b). Honour. Crimes, paradigms and violence against women. London: Zed Books. Wilson, J., Drozdek, B., \& Turkovic, S. (2006). Posttraumatic shame and guilt. Trauma, Violence, \& Abuse, 7(2), $122-141$. 